\title{
Improve Access
}

National Cancer Institute

\section{Source}

National Cancer Institute. Improve Access. NCI Thesaurus. Code C18847.

Support the effective dissemination, communication, and utilization of HIV/AIDS

information to all constituent communities of the NIH. 